\title{
Microwave Irradiation Effect on Intermolecular and Intramolecular Friedel-Crafts Acylation Reaction
}

\author{
Yutaka Okada*, Arisa Fujitsu \\ Department of Applied Chemistry, Ritsumeikan University, Shiga, Japan \\ Email: *ygvictor@sk.ritsumei.ac.jp
}

How to cite this paper: Okada, Y. and Fujitsu, A. (2020) Microwave Irradiation Effect on Intermolecular and Intramolecular Friedel-Crafts Acylation Reaction. Green and Sustainable Chemistry, 10, 18-23.

https://doi.org/10.4236/gsc.2020.101002

Received: January 15, 2020

Accepted: February 10, 2020

Published: February 13, 2020

Copyright $\odot 2020$ by author(s) and Scientific Research Publishing Inc. This work is licensed under the Creative Commons Attribution International License (CC BY 4.0).

http://creativecommons.org/licenses/by/4.0/

\begin{abstract}
The effect of microwave irradiation on the intermolecular and intramolecular Friedel-Crafts acylation of aromatic compounds was investigated. Microwave irradiation had no effect on the intermolecular reaction but had an accelerating effect on the intramolecular reaction. This enhanced intramolecular reactivity that was attributed to the high probability of close proximity between the reaction sites.
\end{abstract}

\section{Keywords}

Microwave Irradiation Effect, Friedel-Crafts Reaction, Cyclization

\section{Introduction}

The Friedel-Crafts acylation of an aromatic compound introduces an acyl group into the aromatic ring to form a new carbon-carbon bond [1] [2] [3]. The acylarenes produced by this reaction are important as reaction intermediates and can be converted into various derivatives. In general, for Friedel-Crafts acylation reactions, acyl chloride is used as the acylating agent and aluminum chloride is used as the catalyst.

In recent years, many studies have examined the reaction accelerating effect of microwave irradiation [4]. Microwaves, which have lower energy than ultraviolet and infrared light, do not directly affect the electronic state of bonding. Nevertheless, under microwave irradiation, reactions can be accelerated because microwaves act directly on polar substances to provide rapid heating. The organic synthesis by microwave irradiation is characterized in that the reaction proceeds at a very high rate and in a high yield. 
In this study, we investigated the effect of microwave irradiation on the acylation of naphthalenes. The rate constants were compared for reactions performed under microwave irradiation conditions and under conventional heating conditions. Similarly, the effect of microwave irradiation on the intramolecular Friedel-Crafts cyclization of benzene derivatives was examined.

\section{Experimental}

\subsection{Substrates}

Substituted naphthalenes and 3-phenylpropanoyl chloride were purchased commercially.

\section{Synthesis of 4-Phenylbutyloyl Chloride}

To a round-bottom flask, 4-phenylbutanoic acid $(25.0 \mathrm{~g}, 152 \mathrm{mmol})$ and thionyl chloride ( $90.4 \mathrm{~g}, 760 \mathrm{mmol}$ ) were added and then refluxed for $3 \mathrm{~h}$. After completion of the reaction, thionyl chloride was removed by distillation to obtain the desired product. Yield: $26.9 \mathrm{~g}$ (96.7\%). ${ }^{1} \mathrm{H}$ NMR $\left(400 \mathrm{MHz}, \mathrm{CDCl}_{3}\right) \delta 7.24$ (d, $2 \mathrm{H}), 7.15(\mathrm{t}, 2 \mathrm{H}), 7.08(\mathrm{t}, 1 \mathrm{H}), 2.84(\mathrm{t}, 2 \mathrm{H}), 2.56(\mathrm{t}, 2 \mathrm{H}), 1.94$ (quin, $2 \mathrm{H}$ ).

\subsection{Friedel-Crafts Reaction}

\subsubsection{Intermolecular Friedel-Crafts Reaction}

To a $200 \mathrm{~mL}$ three-necked flask, 1-methylnaphthalene $(3.45 \mathrm{mmol})$, aluminum chloride (692 mg, $5.18 \mathrm{mmol}$ ), acetyl chloride ( $271 \mathrm{mg}, 3.45 \mathrm{mmol}$ ) or benzoyl chloride (485 mg, $3.45 \mathrm{mmol}$ ) as an acylating reagent, and $5 \mathrm{~mL}$ of 1,2-dichloroethane were added. The mixture was refluxed under microwave irradiation and stirred while sampling at regular intervals. Microwave irradiation was performed using a single-mode microwave reactor ( $\mu$-reactor: Shikoku Keisoku Ltd.). The power was $500 \mathrm{~W}$ operated at $2.45 \mathrm{GHz}$, and the temperature was measured using an optical fiber thermometer. After washing the sample with sodium bicarbonate, the ratio of substrate to product was measured using HPLC. The experiments using 2-methylnaphthalene, 2-chloronaphthalene, and 1-nitronaphthalene as reaction substrates were performed in the same manner.

Each experiment under conventional heating conditions was conducted using the same reaction mixture in the same flask. The reaction was performed under reflux conditions.

1-Acetyl-4-methylnaphthalene: ${ }^{1} \mathrm{H}$ NMR $\left(400 \mathrm{MHz}, \mathrm{CDCl}_{3}\right) \delta 8.70(\mathrm{~d}, 1 \mathrm{H})$, $7.77(\mathrm{~d}, 1 \mathrm{H}), 7.56(\mathrm{~d}, 2 \mathrm{H}), 7.40(\mathrm{t}, 1 \mathrm{H}), 7.33(\mathrm{t}, 1 \mathrm{H}), 7.06(\mathrm{~d}, 1 \mathrm{H}), 2.65(\mathrm{~s}, 3 \mathrm{H})$, $2.54(\mathrm{~s}, 3 \mathrm{H})$.

1-Benzoyl-4-methylnaphthalene: ${ }^{1} \mathrm{H}$ NMR $\left(400 \mathrm{MHz}, \mathrm{CDCl}_{3}\right) \delta 9.15(\mathrm{~d}, 1 \mathrm{H})$, $7.85(\mathrm{~d}, 1 \mathrm{H}), 7.70(\mathrm{~d}, 2 \mathrm{H}), 7.65(\mathrm{~d}, 1 \mathrm{H}), 7.54(\mathrm{t}, 1 \mathrm{H}), 7.48(\mathrm{t}, 1 \mathrm{H}), 7.77(\mathrm{t}, 1 \mathrm{H})$, $7.32(\mathrm{t}, 2 \mathrm{H}), 7.22(\mathrm{~d}, 1 \mathrm{H}), 2.64(\mathrm{~s}, 3 \mathrm{H})$.

2-Acetyl-6-methylnaphthalene: ${ }^{1} \mathrm{H}$ NMR $\left(400 \mathrm{MHz}, \mathrm{CDCl}_{3}\right) \delta 8.22(\mathrm{~s}, 1 \mathrm{H})$, $7.82(\mathrm{~d}, 1 \mathrm{H}), 7.71(\mathrm{~d}, 1 \mathrm{H}), 7.53(\mathrm{~d}, 1 \mathrm{H}), 7.46(\mathrm{~s}, 1 \mathrm{H}), 7.37(\mathrm{~d}, 1 \mathrm{H}), 2.53(\mathrm{~s}, 3 \mathrm{H})$, $2.45(\mathrm{~s}, 3 \mathrm{H})$.

2-Benzoyl-6-methylnaphthalene: ${ }^{1} \mathrm{H}$ NMR $\left(400 \mathrm{MHz}, \mathrm{CDCl}_{3}\right) \delta 8.03(\mathrm{~s}, 1 \mathrm{H})$, 
$7.72(\mathrm{~d}, 2 \mathrm{H}), 7.70(\mathrm{~d}, 1 \mathrm{H}), 7.61(\mathrm{~d}, 1 \mathrm{H}), 7.55(\mathrm{~d}, 1 \mathrm{H}), 7.49(\mathrm{~s}, 1 \mathrm{H}), 7.38(\mathrm{t}, 2 \mathrm{H})$, $7.33(\mathrm{t}, 1 \mathrm{H}), 7.30(\mathrm{~d}, 1 \mathrm{H}), 2.45(\mathrm{~s}, 3 \mathrm{H})$.

\subsubsection{Intramolecular Friedel-Crafts Reaction}

To a $200 \mathrm{~mL}$ three-necked flask, 4-phenylbutanoyl chloride $(3.45 \mathrm{mmol})$, aluminum chloride (692 mg, $5.18 \mathrm{mmol}$ ), and $5 \mathrm{~mL}$ of 1,2-dichloroethane were added. During reflux by microwave irradiation, sampling was performed at regular intervals. Subsequently, the sample was washed with sodium bicarbonate and analyzed by HPLC. The microwave irradiation and temperature measurements were performed in a manner similar to that described for the intermolecular reactions. The experiment using 3-phenylpropanoyl chloride as the reaction substrate was performed in the same manner.

Under conventional heating conditions, the same reaction mixture and flask were used. The reaction was performed under reflux conditions.

3,4-Dihydro-1(2H)-naphthalenone: ${ }^{1} \mathrm{H}$ NMR (400 $\left.\mathrm{MHz}, \mathrm{CDCl}_{3}\right) \delta 7.86(\mathrm{~d}$, $1 \mathrm{H}), 7.40(\mathrm{t}, 1 \mathrm{H}), 7.21(\mathrm{~d}, 1 \mathrm{H}), 7.15(\mathrm{t}, 1 \mathrm{H}), 2.56(\mathrm{t}, 2 \mathrm{H}), 2.55(\mathrm{t}, 2 \mathrm{H}), 1.84(\mathrm{~m}$, $2 \mathrm{H})$.

1-Indanone: ${ }^{1} \mathrm{H}$ NMR (400 MHz, $\left.\mathrm{CDCl}_{3}\right) \delta 7.82(\mathrm{~d}, 1 \mathrm{H}), 7.37(\mathrm{t}, 1 \mathrm{H}), 7.18(\mathrm{~d}$, $1 \mathrm{H}), 7.14(\mathrm{t}, 1 \mathrm{H}), 2.86(\mathrm{t}, 2 \mathrm{H}), 2.72(\mathrm{t}, 2 \mathrm{H})$.

\subsection{Instruments}

The instrumentation and methods used for ${ }^{1} \mathrm{H}$ NMR and HPLC characterization were the same as described in a previous paper [5].

\section{Results and Discussion}

To compare the results under microwave irradiation conditions and conventional heating conditions, the reactions were performed under the same conditions as much as possible. To achieve the same reaction temperature, all reactions were carried out under reflux conditions.

\subsection{Intermolecular Friedel-Crafts Reaction}

The Friedel-Crafts acetylation and benzoylation of naphthalenes were investigated. 1-Acyl-4-methylnaphthalene was obtained as the main product from 1-methylnaphthalene, and 2-acetyl-6-methylnaphthalene was obtained from 2-methylnaphthalene [6]. The acetylation of 2-chloronaphthalene produced several isomers, which were confirmed to be monosubstituted products based on the area ratio of the acetyl hydrogen to the naphthalene ring hydrogen in the ${ }^{1} \mathrm{H}$ NMR spectrum. Table 1 shows the rate constants of these reactions under conventional heating conditions and microwave irradiation conditions. The reaction rate constants were calculated considering second-order reactions between the naphthalenes and the acid chlorides.

As shown in Table 1, for both the Friedel-Crafts acetylation and benzoylation of 1-methylnaphthalene, there was no remarkable difference in reactivity between conventional heating and microwave irradiation. A comparison of the 
Table 1. The measured rate constants of $k(M W)$ and $k(C H)$ of the intermolecular Friedel-Crafts acylation reactions.

\begin{tabular}{cccc}
\hline Substrate & $\begin{array}{c}\text { Acylation } \\
\text { reagent }\end{array}$ & $\begin{array}{c}K(\mathrm{MW}) \times 10^{3} \\
\left(\mathrm{~L} \cdot \mathrm{mol}^{-1} \cdot \mathrm{s}^{-1}\right)\end{array}$ & $\begin{array}{c}K(\mathrm{CH}) \times 10^{3} \\
\left(\mathrm{~L} \cdot \mathrm{mol}^{-1} \cdot \mathrm{s}^{-1}\right)\end{array}$ \\
\hline 1-methylnaphthalene & acetyl chloride & 42 & 45 \\
1-methylnaphthalene & benzoyl chloride & 4.4 & 3.9 \\
2-methylnaphthalene & acetyl chloride & 32 & 29 \\
2-methylnaphthalene & benzoyl chloride & 0.8 & 0.7 \\
2-chloronaphthalene & acetyl chloride & 4.3 & 4.3 \\
1-nitronaphthalene & acetyl chloride & 0 & 0 \\
1-nitoronaphthalene & benzoyl chloride & 0 & 0 \\
\hline
\end{tabular}

acetylation and benzoylation reactions showed that the acetylation reaction proceeded more easily, as is generally known. Similarly, no significant differences were observed between conventional heating and microwave irradiation for the reactions of 2-methylnaphthalene.

Similarly, with 2-chloronaphthalene, which is slightly less reactive, no microwave accelerating effect was observed for the acetylation reaction. With 1-nitronaphthalene, which is known to be less reactive than the other reaction substrates, the reaction did not proceed under either acetylation or benzoylation conditions.

\subsection{Intramolecular Friedel-Crafts Reaction}

The intramolecular Friedel-Crafts reactions of 4-phenylbutanoyl chloride and 3-phenylpropanoyl chloride gave 3,4-dihydro-1(2H)-naphthalenone and 1 -indanone, respectively. Table 2 shows the rate constants for these reactions, as calculated considering first-order reactions for these substrates.

As shown in Table 1, the reaction to form the six-membered ring in 3,4-dihydro-1 $(2 \mathrm{H})$-naphthalenone proceeded more easily than that to form the five-membered ring in 1-indanone. Further, for each reaction, the reaction rate constant under microwave irradiation conditions was larger, and this enhancement was particularly remarkable for the reaction in which the six-membered ring was formed.

\subsection{The Comparison between Intermolecular and Intramolecular Reactions}

In the intermolecular Friedel-Crafts reactions investigated in this study, no reaction accelerating effect was observed. In contrast, a reaction accelerating effect was observed for the intramolecular Friedel-Crafts reactions.

In general, the major difference between an intermolecular reaction and an intramolecular reaction is the magnitude of the entropy change, as an intermolecular reaction in which two molecules react has a more negative activation entropy [7]. As the absolute value of the activation entropy is smaller in an 
Table 2. The measured rate constants of $k(M W)$ and $k(C H)$ of the intramolecular Friedel-Crafts acylation reactions.

\begin{tabular}{ccc}
\hline Substrate & $K(M W) \times 10^{4}\left(\mathrm{~s}^{-1}\right)$ & $K(\mathrm{CH}) \times 10^{4}\left(\mathrm{~s}^{-1}\right)$ \\
\hline 3,4-dihydro-1(2H)-naphthalenone & 28 & 21 \\
1-hydroindone & 7.3 & 4.2 \\
\hline
\end{tabular}

intramolecular reaction, there is a high probability that the reaction sites will approach each other. In other words, in an intramolecular reaction, an accelerating effect was observed because the microwave energy could be absorbed by the state in which the reaction sites were close to each other.

\section{Conclusion}

The effect of microwave irradiation on intermolecular and intramolecular Friedel-Crafts acylation reactions was examined. The acylation of naphthalenes was used as a model intermolecular reaction, whereas the cyclization on benzene derivatives was used as a model intramolecular reaction. In comparison with conventional heating conditions, microwave irradiation was found to have no accelerating effect on the intermolecular Friedel-Crafts reaction, whereas an accelerating effect was observed for the intramolecular Friedel-Crafts reaction. This effect was attributed to microwave irradiation increasing the probability that the reaction sites were in close proximity to each other in the transition state for the intramolecular reaction.

\section{Conflicts of Interest}

The authors declare no conflicts of interest regarding the publication of this paper.

\section{References}

[1] Zhang, J., Kirchhoff, E.M., Zembower, D.E., Jiminez, N., Sen, P., Xu, Z.Q. and Flavin, M.T. (2000) Automated Process Research. An Example of Accelerated Optimization of the Friedel-Crafts Acylation Reaction, a Key Step for the Synthesis of Anti-HIV (+)-Calanolide A. Organic Process Research \& Development, 4, 577-580. https://doi.org/10.1021/op0002038

[2] Anderson, K.W. and Tepe, J. (2002) The First Intermolecular Friedel-Crafts Acylation with $\beta$-Lactams. Organic Letters, 4, 459-461. https://doi.org/10.1021/ol010291w

[3] Reeve, A.M. (2004) A Discovery-Based Friedel-Crafts Acylation Experiment: Student-Designed Experimental Procedure. Journal of Chemical Education, 81, 1497-1499. https://doi.org/10.1021/ed081p1497

[4] Ghosh, S. and Mukhopadhyay, C. (2017) Microwave Syntheses: A Modern Day Approach towards Sustainable Chemistry. Current Microwave Chemistry 4, 287-305. https://doi.org/10.2174/2213335604666170830122722

[5] Pramesti, I.N. and Okada, Y. (2017) Iron (III) Chloride Catalyzed Claisen Rearrangement Reaction of Allyloxyarenes under Microwave Conditions. Green and Sustainable Chemistry, 7, 234-245. https://doi.org/10.4236/gsc.2017.73018

[6] Yuan, B., Li, Z.S., Liu, Y.J. and Zhang, S.C. (2008) Liquid Phase Acylation of 
2-Methylnaphthalene Catalyzed by H-Beta Zeolite. Journal of Molecular Catalysis $A$, A280, 210-218. https://doi.org/10.1016/j.molcata.2007.11.004

[7] Wang, J.P., Zheng, K.C., Lin, B.B. and Weng, Y.P. (1998) A Comparative Study of Inter- and Intramolecular C-H Aminations: Mechanism and Site Selectivity. RSC Advances, 7, 34783-34794. https://doi.org/10.1039/C7RA05032A 